\title{
Assessment of the level of economic security of construction companies
}

\author{
Julia Leskova ${ }^{1, *}$, Evgenia Rudenko², Lubov Netishinskaya ${ }^{2}$, and Igor Kotov ${ }^{1}$ \\ ${ }^{1}$ The Russian Presidential Academy of National Economy and Public Administration, Vernandskogo \\ avenue, 82/1, Moscow, Russia, 119571 \\ ${ }^{2}$ Federal State Budgetary Educational Institution of Higher Education "Kuban State Agrarian \\ University named after I.T. Trubilin”, Kalinina str., 13, Krasnodar, Russia, 350044
}

\begin{abstract}
In 2020, the President of Russian Federation outlined new national goals in the form of achieving "digital maturity" of key sectors of the economy and social sphere (Presidential Decree No. 474 of July 21, 2020 "On the national development goals of Russian Federation for the period up to 2030") ... At the meeting of working group of State Council in January 2020, the head of the Ministry of Telecom and Mass Communications named seven areas of development of digital economy in the interests of citizens, business and the state, including "Digital economy - to business: drastic reduction of costs" and "Digital economy - to business: reduction of administrative pressure". To create the conditions for introduction of new digital technologies in construction activities within the framework of "Digital Economy" program, a subgroup "Digital technologies for managing the development of territories and urban planning policy" was created. The current period - the period of a pandemic (its consequences) and introduction of a number of restrictions for a number of sectors of the economy - is also becoming a new stage for the implementation of digitalization in construction activities. The COVID-19 pandemic is one of those external threats that are unpredictable. It is impossible to predict their appearance, peculiarities of the course. As noted in the economic literature, this greatly complicates the counteraction, since it is impossible to develop a coherent and effective strategy of this kind in advance. Moreover, it is impossible to predict the duration of consequences of this threat, as well as the list of risks and threats to the economic security of construction enterprises caused by the COVID-19 pandemic.
\end{abstract}

\section{Introduction}

At the present stage, various digital technologies have been introduced into construction activities both in Russia and at the global level. In addition, the implementation process is constantly being updated. Thus, attempts are being made to use the digital technology "Smart city" - world-famous urban planning concepts for the integration of a variety of information and communication technologies (ICT), including Internet of Things (IoT)

${ }^{*}$ Corresponding author: yuliyleskova@yandex.ru 
systems for managing urban infrastructure: transport, education, T.N. Orlovskaya singles out the 3D modeling system developed by St. Petersburg specialists as the most interesting and promising for the development of construction industry, and for the formation and development of smart cities in Russia. It allows visualizing the investment and construction proposals, to assess the degree of influence of building processes on the appearance of the city, to determine the change in standard / normative characteristics of quality of life, etc.

\section{Methods}

An approximate (preliminary) list looks currently as follows: a decrease in demand for construction products, an increase in prices for construction materials, finished construction projects; problems with the provision of labor resources. In these conditions, the Government of Russian Federation is developing a number of new rules aimed at supporting business and entrepreneurship in general. It also adopts a national action plan to ensure the restoration of employment and incomes of population, economic growth and long-term structural changes in the economy (approved at a meeting of the Government of Russian Federation on September 23, 2020 (Minutes No. 36, Section VII) No. P13-60855 dated October 2, 2020.), in which, in order to launch a new investment cycle and improve the business climate, it provides for the following key initiatives in relation to construction: a) "new rhythm of construction": acceleration of construction procedures, reforming the regulatory legal framework for urban planning and construction; b) digitalization of construction industry: creation of a single digital space in construction, the use of a digital model of an object during its life cycle.

The foregoing emphasizes the need to conduct a study on the issues of economic security of construction enterprises in the digital economy and determine its legal ways of protecting against external and internal threats.

The methodological basis of the study includes: economic analysis, sociological analysis, which made it possible to establish the presence of negative consequences of emerging economic threats. The dialectical method, methods of analysis and synthesis, induction and deduction, comparison and generalization were used to show various indicators of construction industry. Formal legal analysis made it possible to identify and investigate the legislative basis of the issue under consideration.

The study made it possible to identify the main new economic threats to the security of construction enterprises, which are associated with the digitalization of the economy (construction industry) developing during a pandemic and economic recovery after business self-isolation. The authors have proposed some ways to neutralize the negative consequences of these threats. The main attention is paid to assessing the use of selfregulation methods in the construction industry.

According to the Rosstat data, the volume of Russia's gross domestic product (hereinafter referred to as GDP) for 2020 (during the transition to the digital economy), according to the first estimate, amounted to 106606.6 billion rubles at current prices. The index of its physical volume relative to 2019 was $96.9 \%$. The GDP deflator index for 2020 in relation to the prices of 2019 was $100.7 \%$. The gross value added in the construction industry in terms of GDP in 2020 amounted to 5458.1 billion rubles [4, p. 7]. The volume of construction work in 2020 is 9497.8 billion rubles, or $100.1 \%$ (in comparable prices) to the level of 2019, in December 2020 - 1244.3 billion rubles, or $100.9 \%$ to the corresponding period of the previous year [4, p. 81]. Construction activity, as shown by the above data, is an important indicator in determining the indicators of GDP. In addition, as A. Glushkov rightly notes, "When construction is underway, up to 10 related sectors of the economy start moving. We spoke during the restrictive measures, and we say now: construction should not stop for a single day, then the entire economy will work" [5]. As 


\section{EMMFT-2020}

rightly noted in doctrinal sources, in the modern economy, the safety of construction industry takes a leading position in the overall system of ensuring the country's security [6].

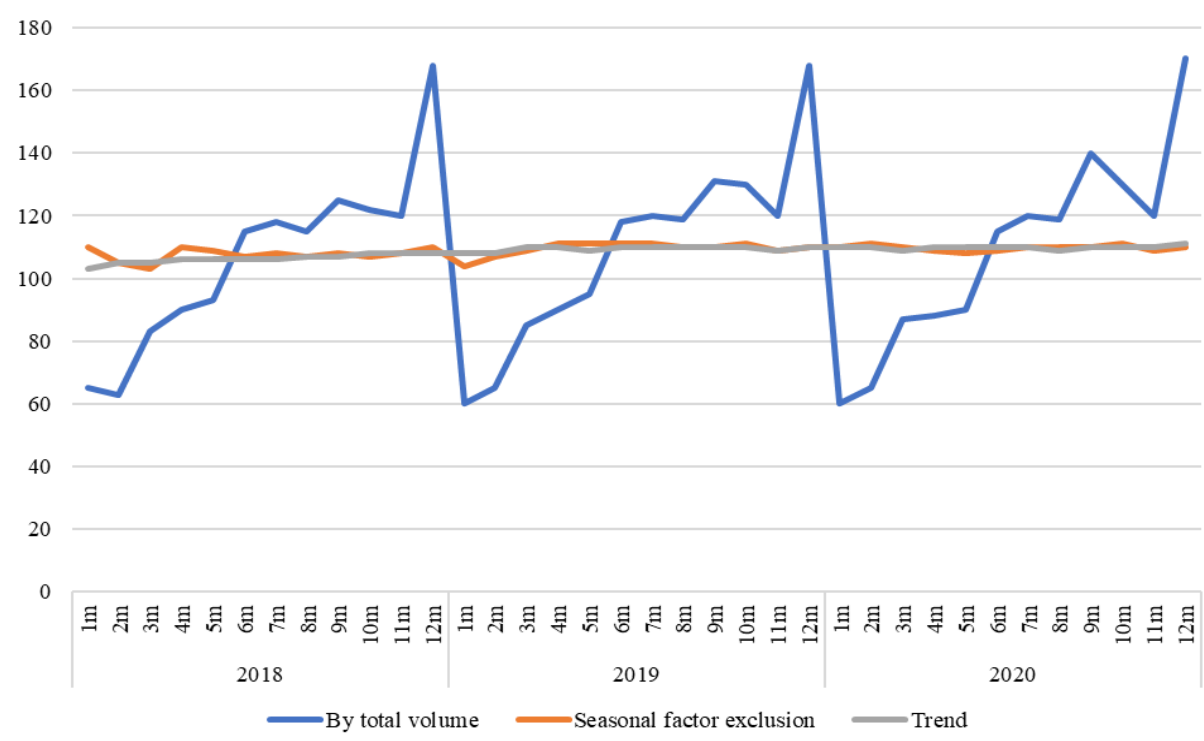

Fig. 1. "Dynamics of the volume of work performed by the type of activity "Construction" in\% to the average monthly value of 2017".

In addition, the following tourism and sports facilities were introduced in 2020: tourist camps for 770 places, motels for 404 places, campgrounds for 107 places, 29 swimming pools with a track length of 25 meters and 50 meters, 28 sports facilities with artificial ice, 134 fitness centers, gyms with an area of 142.5 thousand square meters, stadiums for 22.7 thousand. places [4, p. 92].

In a generalized form, the factors that influenced the performance indicators of construction enterprises in 2020 are presented in Figure 2.

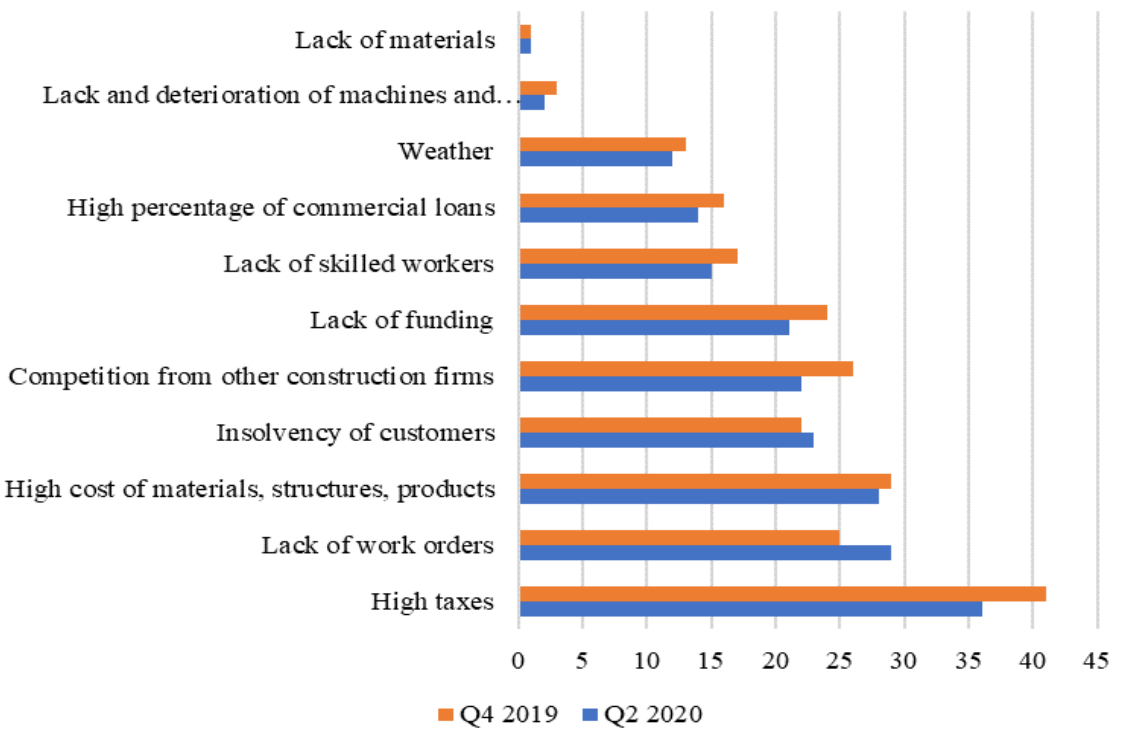

Fig. 2. "Factors limiting production activities of construction companies". 
The above indicators of dynamics of construction work (which could have been much higher, in our opinion, if not for the impact of external and internal threats on the economic security of construction business) are primarily associated with the assessment of external and internal threats to economic security of construction business. Among such threats at present, one should first of all highlight the digitalization of the economy, which took place during the pandemic (COVID-19), which affects the above indicators. In this study, taking into account the relevance of these problems, we will focus on the specific threats mentioned above and show exactly how they can be "neutralized" using not only state methods, application of measures and regimes of a construction corporation itself, but also with the help of other legal means of protecting the economic security of construction industry (self-regulation of construction industry).

This study was carried out on the basis of an economic analysis of constituent indicators of construction industry, in order to find the most optimal alternative to state support as a way to protect against external and internal threats. Among such legal methods, the authors highlight the self-regulation of construction industry, which has a number of functions to neutralize emerging threats (security, regulatory factors).

The purpose of the work is to assess emerging threats to the economic security of construction enterprises, affecting, among other things, the index of entrepreneurial confidence of entrepreneurs - construction companies, as well as to find legal ways (means) to create an optimal system of influence on the construction industry, excluding negative consequences of external and internal threats to economic security of a construction company.

The novelty of the study lies in the formulation, substantiation and solution of problems on the impact of such an external threat on the economic security of construction companies as digitalization of the economy, formation of which is carried out during the pandemic (COVID-19) and after it, in building a position on identifying and substantiating a new legal method to neutralize these threats - self-regulation of construction industry.

The study is based on an economic analysis of indicators of construction industry in 2020, which have undergone significant changes compared to 2018-2019. as a result of emergence of new external threats to economic security (the study is based on the Rosstat data for the period of 2020, the report of the association of self-regulatory organizations in the construction industry - the National Association of Builders on its activities in 2020).

Among the legislative norms that ensure economic security, one should name, for example, the Urban Planning Code of Russian Federation, or the Decree of the Government of Russian Federation of 24.07.2017 No. 878 (as amended on 31.12.2019) "On the procedure for forming a unified state register of conclusions examination of design documentation for capital construction projects and amendments to the Government Decree of March 5, 2007 No. 145", etc.

In addition, the authors turned to the analysis of regulatory framework to assess the possibility of creating an optimal model of economic security of construction companies. It should be noted that ensuring economic security is achieved through the establishment of rules for the implementation of construction activities by legal norms, which establish the characteristics of quality criteria and parameters (threshold values). These rules are enshrined not only by the construction companies to ensure their economic security, but can also come from state and non-state actors (associations of builders - self-regulatory organizations (hereinafter - SRO), the association of SROs in the field of construction - the National Association of Builders (hereinafter - Nostroy) and are aimed at the smooth functioning of the entire construction complex. Therefore, the study is also based on the analysis of specified Nostroy documents. In addition to the specified regulatory acts in the field of construction, one should also pay attention to the standards and rules for the 
implementation of construction activities of the SRO), which are also aimed at ensuring the economic security of construction companies.

\section{Discussion}

Digitalization of construction industry is becoming that external threat the authors would like to draw attention to and assess its consequences. As N. N. Zaguskin rightly notes, the transition to digital economy poses a serious threat to construction companies if they do not learn to live in a dynamic world of constant innovation, do not become generators of new ideas, and do not actively use information and communication technologies [7, p. 160]. However, the Government of Russian Federation regards the introduction of digitalization not as an economic threat, but as an important event included in the National Action Plan to ensure the restoration of employment and incomes of the population, the economy and long-term structural changes in the economy (approved at a meeting of the Government of Russian Federation on September 23, 2020 (Minutes No. 36, Section VII) N P13-60855 of October 2, 2020). The digitalization of the construction industry can be considered as an economic threat to the security of a construction enterprise, since up to the present there are problems and limitations for the introduction of digital technologies in the named sector of the economy, which include, first of all, the high cost of their implementation, insufficient digitalization of suppliers, high risks of introducing new digital technologies, as well as it can be imposed sanctions on foreign software. Among the problems of digital economy in Russia, foreign companies (The Boston Consulting Group) name the underestimation of current digital opportunities and their impact on the efficiency, productivity and business growth potential in the construction industry $[8, \mathrm{p} .6]$.

A sociological survey of Russian construction companies (more than 70 companies with different scales of activity, level of integration in the chain and specialization took part in the survey) conducted by Strategy Partners, which is one of the top 3 strategic consultants of Russian market, clearly confirms this (see Figure 3).

\begin{tabular}{|c|c|c|c|c|}
\hline & $\begin{array}{l}\text { I completely } \\
\text { agree }\end{array}$ & $\begin{array}{l}\text { I partly } \\
\text { agree }\end{array}$ & $\begin{array}{l}\text { Probably } \\
\text { not }\end{array}$ & \\
\hline $\begin{array}{l}\text { The high cost of introducing digital } \\
\text { technologies }\end{array}$ & $36 \%$ & $56 \%$ & $8 \%$ & \multirow{3}{*}{$\begin{array}{l}\text { Key challenges } \\
\text { and constraints } \\
\text { for digital } \\
\text { technologies } \\
\text { adoption }\end{array}$} \\
\hline $\begin{array}{lll}\begin{array}{l}\text { Insufficient } \\
\text { suppliers }\end{array} & \text { digitalization } & \text { of } \\
\end{array}$ & $40 \%$ & $44 \%$ & $16 \%$ & \\
\hline $\begin{array}{l}\text { High risks of introducing digital } \\
\text { technologies }\end{array}$ & $28 \%$ & $56 \%$ & $16 \%$ & \\
\hline $\begin{array}{ll}\text { Insufficient qualifications } & \text { of } \\
\text { company personnel } & \end{array}$ & $12 \%$ & $68 \%$ & $20 \%$ & \\
\hline $\begin{array}{l}\text { Low importance / effectiveness of } \\
\text { digital technologies for business }\end{array}$ & $8 \%$ & $52 \%$ & $40 \%$ & \multirow{3}{*}{$\begin{array}{l}\text { Problems and } \\
\text { limitations that } \\
\text { are not an } \\
\text { obstacle to the } \\
\text { introduction of } \\
\text { digital }\end{array}$} \\
\hline $\begin{array}{l}\text { Lack of supply and suppliers of } \\
\text { digital solutions in the Russian } \\
\text { market }\end{array}$ & $28 \%$ & $28 \%$ & $44 \%$ & \\
\hline Regulatory restrictions & $20 \%$ & $24 \%$ & $56 \%$ & \\
\hline
\end{tabular}

Fig. 3. "Key limitations and problems of introducing digital technologies based on the results of a survey of respondents, $\%$ of respondents".

Often, digitalization is associated with concerns about job cuts, minimizing the impact of human factor on management, and making decisions based on digital data. These fears, according to L. A. Borisova and M. Kh. Abidov, to a certain extent are justified, since a person is characterized by cognitive errors, and decision-making based on data is more 
rational and more valuable for business [9]. However, digitalization makes it possible to reduce routine and purely technical actions (work), freeing up time for creative solutions. Speaking about the digitalization of construction in its various manifestations, one must always remember both the positive effect of its implementation and the negative one (which we have briefly analyzed).

Foreign economists and lawyers assess the digitalization of construction industry positively, considering its advantages from a slightly different angle. First of all, due to the fact that the harmonization of digital technologies and law allows foreign construction companies to widely use standard construction contracts, which are widely studied in doctrinal sources for the fact of their effectiveness in building relationships in the construction business. According to D.R. Scheer, the use of digital technologies allows not only to draw a project, but also to simulate the "behavior of a building" in the event of seismic activity.

Another external threat of the "new" generation, which fell on the period of digitalization of the economy, was the pandemic (COVID-19), which resulted in selfisolation. As I. S. Lola and G. V. Ostankovich rightly point out, "given the rather weak potential of business activity at the disposal of construction organizations at the entrance to the pandemic funnel and the unprecedented nature of this phenomenon in general, their chances of resisting the primary and even more subsequent associated negative events in economic space turned out to be minimal". This is confirmed by the drop in the entrepreneurial confidence index. So, the specified index in the 2nd quarter compared to the 1 st showed its fall to critical indicators $(-24 \%)$ (see the figure below).

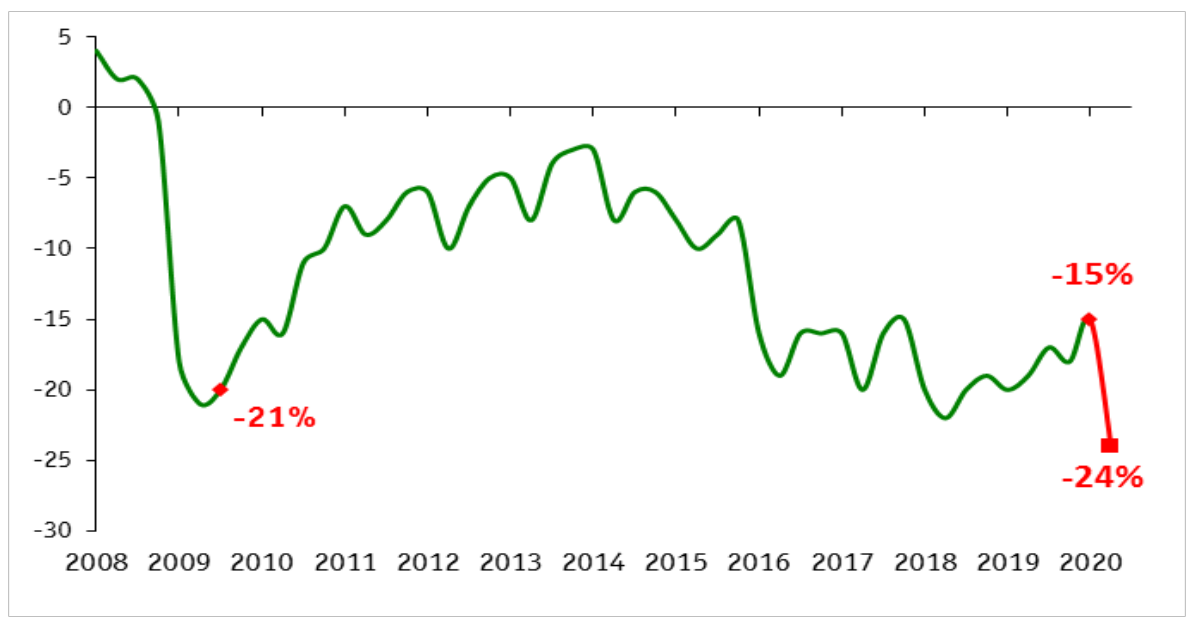

Fig. 4. "Dynamics of ECI in construction in\%".

The recorded decline in the entrepreneurial confidence index has become an absolute anti-record over the past more than ten years, and against the background of "relative success" of its timid recovery during several development periods preceding the pandemic, the recorded changes look, in our opinion, especially critical and deplorable.

The entrepreneurial confidence index consists of several indicators that influence it. In this study, we will focus on individual indicators that most clearly allow us to build an assessment of such an external threat as a pandemic. Firstly, the result of the pandemic was a decrease in the number of construction contracts concluded. Secondly, construction companies are faced with a lack of labor (there is an outflow of migrants) and job cuts, and, as a consequence, a lack of professional staff. Among the specialties for which the largest outflow of foreign labor is noted: handyman (35\%), plasterer $(27 \%)$, bricklayer $(27 \%)$, concrete worker (26\%), reinforcement worker (19\%), painter (19\%), installer (14\%), facing 
$(13 \%)$, excavator $(13 \%)$, roofer $(12 \%)$, welder $(11 \%)$, road worker $(11 \%)[14]$. What has been said about the dynamics of work and the number of employees at a construction enterprise can be clearly seen in the figures (graphs) below.

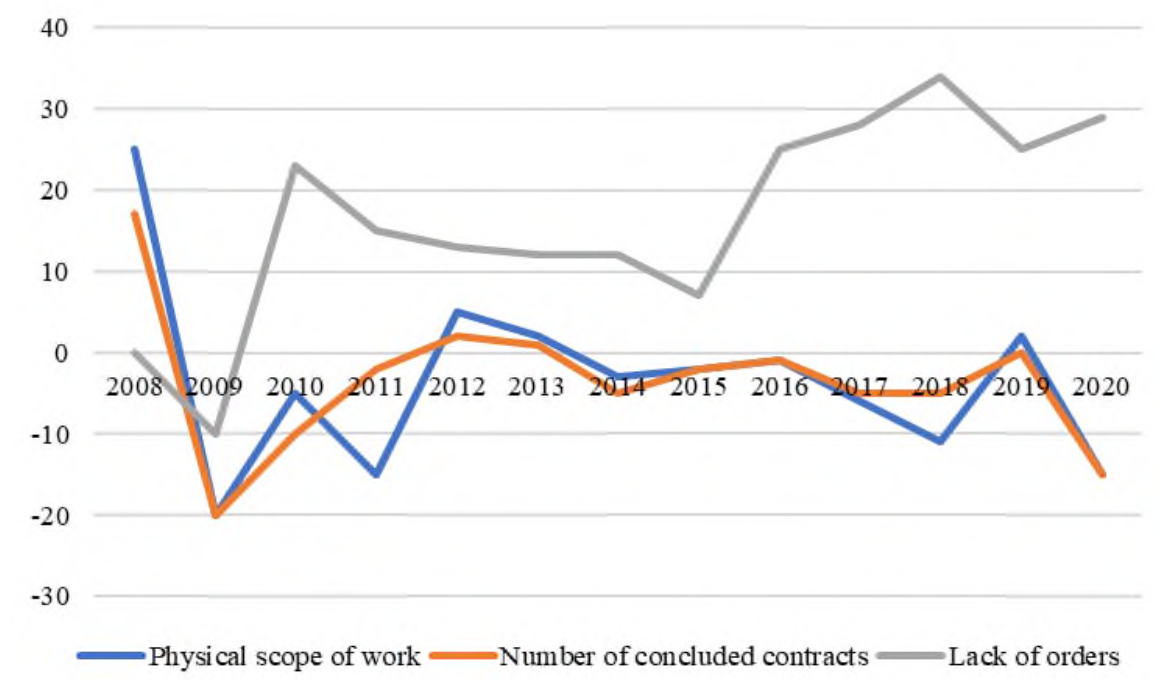

Fig. 5. "Dynamics of estimates of physical volume of work, the number of concluded contracts and the limiting factor - "lack of orders"".

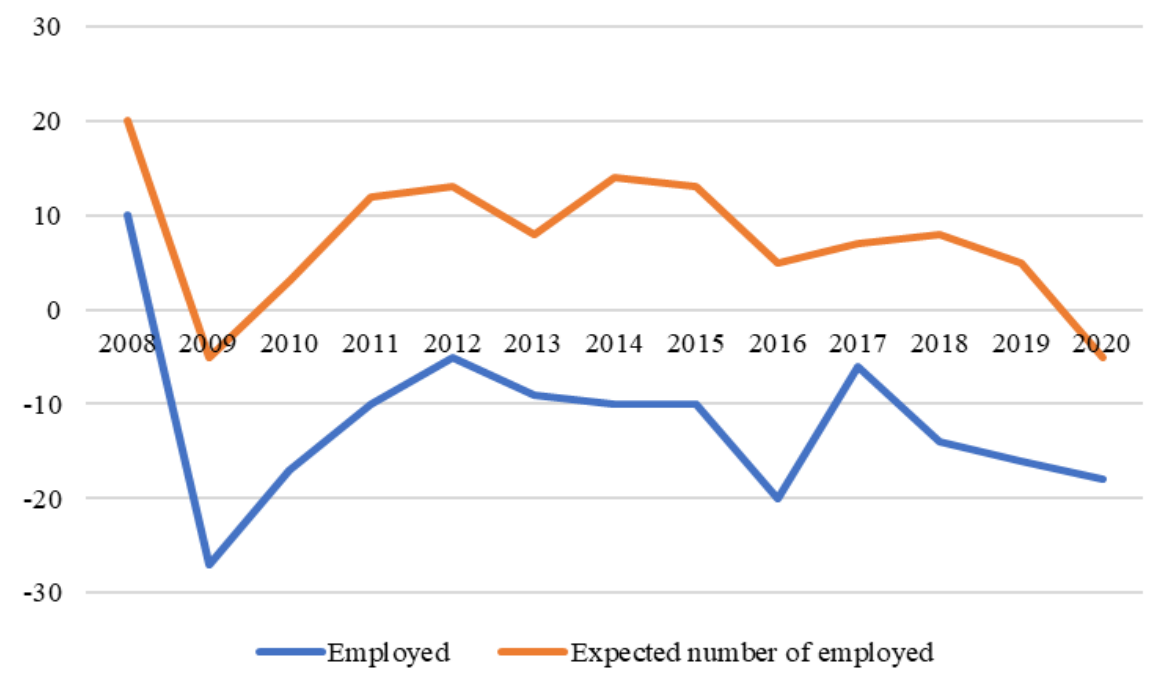

Fig. 6. "Dynamics of current and expected estimates of the number of employees".

Despite the fact that the construction industry has experienced such an economic threat as a pandemic, one should nevertheless agree with the point of view of economists, that the state of the business climate in the construction industry is more encouraging in terms of economic development and economic security than in other sectors of the economy. (tourism, industry). The above analysis shows that the indicators of entrepreneurial confidence in the construction business suffered greatly and influenced the economic security of construction enterprises. The pandemic highlighted weaknesses in the economic 
security of construction industry, highlighted weak adaptations and moved construction into a low risk tolerance range (see Figure 7)

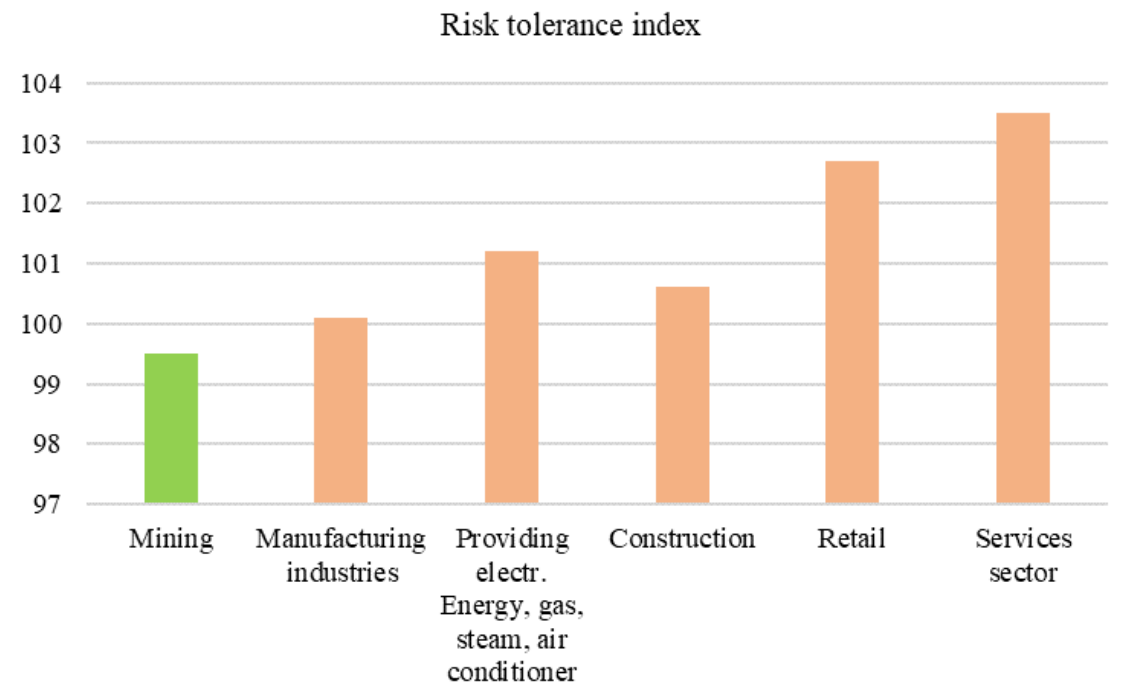

Fig. 7. "Risk tolerance index in the context of key segments of Russian economy".

In 2021, economists' forecasts are rosier: the share of organizations that are predicted to increase the volume of work is less than the share of those who expect it to decrease; it is expected that the balance of estimates of changes in the indicator will be $(-8 \%)$. According to the forecast, an increase in the physical volume of work is expected by $18 \%$ of heads of organizations, a decrease - by $26 \%$ of managers.

\section{Results}

The assessment of some external and internal threats to the safety of construction companies allows us to conclude that it is necessary to introduce new (innovative) mechanisms and methods of economic influence in the construction industry, which would exclude the presence of these threats. Among such methods of "neutralizing" economic threats in construction, as we have indicated earlier, is self-regulation, which functions in Russia in the form of self-regulatory organizations, the assessment of whose activities we will conduct in the next paragraph.

SROs in the construction industry have a number of economic functions that allow them to influence the course and economic development of both the construction industry as a whole and the activities of construction business participants who are its members. First, there is a shortage of information technology specialists currently in the construction industry. Therefore, SROs can become those organizations on the platforms of which its members undergo training in order to acquire knowledge on the use of information technologies. Thus, SROs will be "guides" to the world of digital economy.

Secondly, SROs in the construction sector have an impact on the development of legislative framework for the activities of participants in the construction industry. This is possible through the participation of representatives of SROs in the field of construction in the activities of collegial bodies of NOSTROY. NOSTROY committees initiatives appear, which receive further progress in the legislative bodies. In the structure of NOSTROY there are 11 collegial bodies of various profiles, and in the commissions and committees there are 
400 positions for representatives of SROs in the construction sector. However, the specified number of positions is unevenly distributed among SROs in the construction sector: a) 118 SROs (more than half) do not have their representatives in the collegial bodies of NOSTROY and participate in decision-making only when holding district conferences and the All-Russian Congress; b) 75 SROs participate in the work of one or two collegial bodies of NOSTROY; c) 29 construction SROs sent their representatives to three or more NOSTROY management bodies. This, in our opinion, is due to the fact that builders do not fully use the self-regulation mechanism, do not fully understand the possibilities of its effective action, including its impact on the legislative basis of their activities.

Thirdly, in order to improve the quality of construction work provided by SRO members in the field of construction, a mandatory requirement for membership in an SRO in the field of construction is the presence of at least 2 specialists among the employees of a construction enterprise, information about which is included in the National Register of Construction Specialists. The presence of these specialists with certain knowledge in the field of construction allows building the work of construction enterprises in accordance with the requirements and parameters that must be observed in the construction market.

SROs in the field of steel construction in 2020-2021 are also important neutralizers of consequences of the pandemic, which cannot but be taken into account when determining their role in the construction business and the impact on the elimination of this economic threat. First of all, SROs in the construction sector have taken an active stance in resolving the issue of stabilizing prices for construction materials and work during a pandemic. During a pandemic (especially with the self-isolation of construction business), there was a huge jump in the growth of prices for construction work and building materials. So, as of May 12, 2020, according to the monitoring of the cost of building materials conducted by the Situation Center NOSTROY to support builders in 37 regions, an increase in the cost of building materials from $4 \%$ to $16.99 \%$ was recorded in 23 constituent entities of Russian Federation (Nostroy website. URL: https://nostroy.ru).

The participation of SROs in the field of construction together with state bodies (Ministry of Construction) made it possible to establish and approve indices of changes in the estimated cost of construction in 2020 using the calculation method in 79 constituent entities of Russian Federation, which was a partial solution to the issue of growth in the cost of building materials (Nostroy website. URL: https://nostroy.ru).

In addition to the above, SROs in the field of construction, in order to eliminate the adverse property consequences of SRO members after the pandemic, have become entities that provide participants in the construction industry (SRO members) with material support in addition to the state. As of January 13, 2021, 105 SROs in the construction sector made a decision to provide loans to their members and approved in a new edition such an internal corporate document as a regulation on a compensation fund for contractual obligations.

The size of loans issued by construction SROs to their members, as of September 23, 2020 , is already 1.228 billion rubles. 49 construction companies registered in 14 constituent entities of Russian Federation received 52 loans. Under 30 agreements (of which 15 agreements are only for the payment of wages, 15 are mixed agreements), loans in the amount of 425.36 million rubles have been provided to pay wages to employees of SRO members. Taking into account the size of the average monthly salary in the construction industry, which amounts to 44,074 rubles, this amount covers the wages of almost 10 thousand people per month. Under another 37 contracts, loans in the amount of 802.7 million rubles were provided for the purchase of building materials, structures, equipment for performing work under 52 contract contracts concluded before April 1, 2020 with a total value of almost 8.5 billion rubles. 


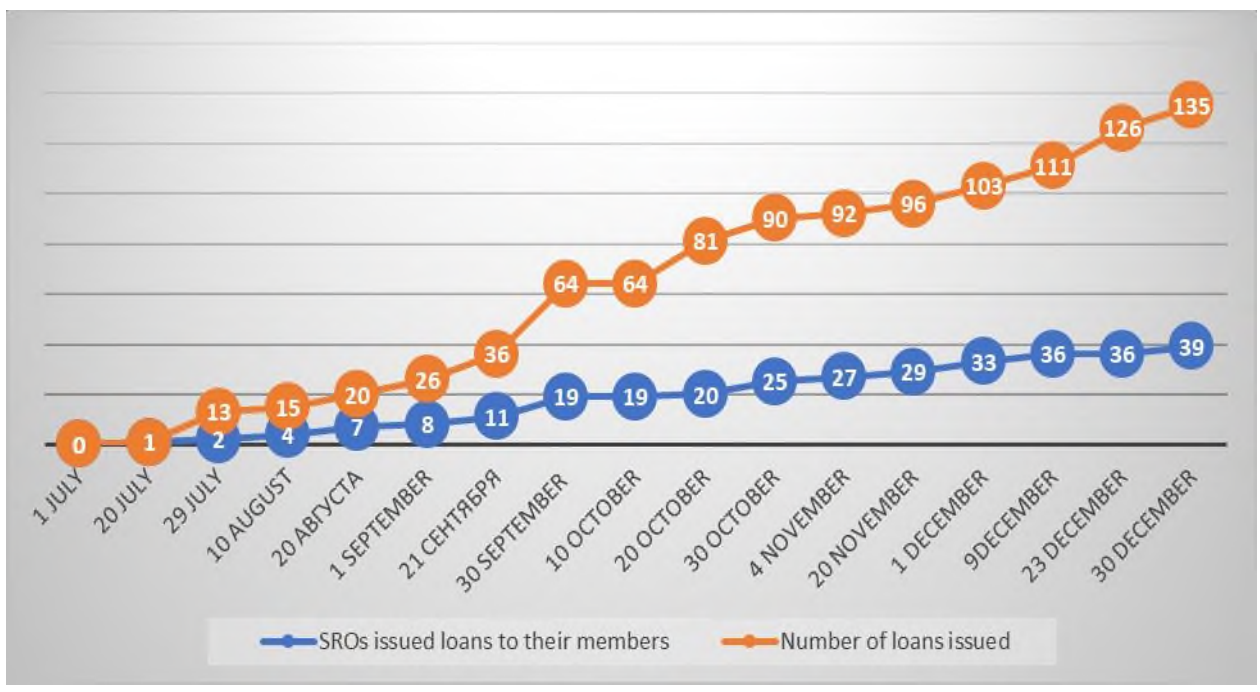

Fig. 8. Dynamics of holding general meetings of SROs and issuing loans.

As shown in Figure 9, dynamics of holding general meetings of SROs and their issuance of loans is growing, therefore, at the end of December 2020, the State Duma extended the right to issue loans to members of SROs in the construction sector until January 1, 2022 (previously the deadline was set to December 31, 2021). As it turned out, the period after the lifting of restrictions in connection with the coronavirus infection turned out to be not so "rosy" for the construction business, many construction enterprises - small and medium-sized businesses faced new problems related to how to "survive" after a long shutdown of the economy in Russia and abroad, and SRO loans in the construction sector have become a "breath of air" in this situation. These loans are an alternative to obtaining loans for small and medium-sized businesses, moreover, the interest on the loan cannot be more than the key rate. The benefits of loans are obvious. Firstly, the lending rates are higher than the interest on loans (on November 2, 2020, B. Titov, authorized by the President of Russian Federation for the protection of rights of entrepreneurs, proposed to reduce the loan rate to 6.25 per annum ("the key rate of the Central Bank $+2 \%$, we get the value $6,25 \%$ ") (the national project" SMEs and support for individual entrepreneurial initiative" included an item on the development of concessional lending mechanisms for small and medium-sized enterprises with a reduced interest rate - no higher than $7 \%$ per annum from 2021, in the previous version of the national project the maximum rate on concessional loans for SMEs under the program of Ministry of Economic Development amounted to $8.5 \%$ ). At the same time, Yu. Titov emphasizes that it is not easy for a small and medium-sized enterprises to obtain a loan "in any case, because the requirements for collateral are very high, it is necessary to replace at least some of these requirements with guarantees from development institutions. It is also unprofitable for banks to lend to small businesses because of high requirements for creating reserves, which the Bank of Russia requires as a Loans in case of loan default. There were proposals to cancel the reservation during the pandemic. The risks are high for the entire economy and for the whole society, and they can be reduced only by the full support of business". The implementation of rules on loans to SROs in the construction sector after January 1, 2021 and expanding the list of sources of financing for the provision of loans to SROs in the construction sector to their members can become an effective anti-crisis legal means of solving the socio-economic problems of construction business, as well as the consumer of construction product and the 
state. Also, SRO loans in the construction sector, in our opinion, are an excellent alternative to lending in banks to small and medium-sized businesses.

\section{Conclusion}

The economic security of construction enterprises as a state of its protection from external and internal threats is achieved in various ways. The choice of one method or another depends on the assessment, first of all, of the level of economic security, the influence of external and internal threats on it. In the context of formation of digital economy against the background of consequences of pandemic, it is necessary to apply not only to several state forms and methods of supporting the construction business, but also others related to new methods of influencing the construction industry. As the assessment of activities of SROs in the construction industry and their impact on the elimination of threats to economic security on the construction business has shown, these organizations are an important assistant to the state in neutralizing the consequences of external and internal threats to the economic security of construction companies (digitalization of the economy, a pandemic, rising prices, product quality, etc.).

\section{References}

1. T.N. Orlovskaya, BIM-modeling in the tasks of construction and architecture: materials of the II International Scientific and Practical Conference (St. Petersburg, 2019)

2. I.G. Shindikova, V.A. Plotnikov, Management of socio-economic development of regions: collection of scientific articles (Kursk, 2020)

3. E.S. Lavrinova, Research of the innovative potential of society and formation of directions for its strategic development: a collection of scientific articles of the 8th AllRussian scientific and practical conference with international participation (Kursk, 2018)

4. N.N. Zaguskin, Scientific notes of the international banking institute 22, 148-162 (2017)

5. B. Bank et al., Russia online? Catch up cannot be left behind (The Boston Consulting Group, Boston, 2016)

6. L.A. Borisova, M.Kh. Abidov, UEPS 3 https://cyberleninka.ru/article/n/problemy-tsifrovizatsii-stroitelnoy-otrasli

7. B. Eggleston, The NEC 3 Engineering and Construction Contract. A Commentary. 2nd ed. (Blackwell Science, Oxford, 2006)

8. C.K. Haswell, D.S. de Silva, Civil Engineering Contracts: Practice \& Procedure (Butterworth, London, 1989)

9. D.R. Scheer, The Death of Drawing: Architecture in the Age of Simulation (Routledge, 2014)

10. I.S. Lola, G.V. Ostankovich, Business climate in construction in the II quarter of 2020 (NII HSE, M., 2020)

11. A.V. Kopytova, N.S. Zotkina, I.G. Reshetnikova, MATEC Web of Conferences 239, 04012 (2018) DOI: 10.1051/matecconf/201823904012

12. R. Kolobov, U. Filatova, V. Borshcheniuk, N. Semerianova, D. Bayanov, E3S Web of Conferences 110, 02095 (2019) DOI: 10.1051/e3sconf/201911002095 
13. Y.V. Truntsevsky, I.I. Lukiny, A.V. Sumachev, A.V. Kopytova, MATEC Web of Conferences 170, 01067 (2018) DOI: 10.1051/matecconf/201817001067

14. N. Semeryanova, O. Fedorenko, A. Kopytova, MATEC Web of Conferences 239, 04013 (2018) DOI: 10.1051/matecconf/201823904013 